\title{
Small-bowel metastasis of malignant melanoma: video capsule endoscopy appearance
}

Techniques such as helical computed tomography (CT), [ $\left.{ }^{18} \mathrm{~F}\right] 2$-fluoro-2-deoxyD-glucose positron emission tomography (fDg-PET)/CT, and capsule endoscopy have replaced the former, less sensitive diagnostic tools for the detection of small-bowel tumors. Identification of tumors by capsule endoscopy has been described in the past few years [1,2]. Malignant melanoma has a high predisposition to metastasize to the gastrointestinal tract. The presence of small-bowel metastasis of melanoma influences its management, since current modalities of treatment include surgical resection, which increases overall survival [3]. The coalblack appearance of melanoma on capsule endoscopy was first described by Smedegaard [4]. Here, we present the capsule endoscopic appearance of this typical type of melanoma metastasis.

A melanoma was found on the left foot of a 49-year-old man in 2004 and was treated by surgical excision. In subsequent years, cutaneous and lymph metastases were treated by local excision, interferon $A$, and dendritic cell-based vaccination. The patient was considered to be in remission when, in November 2009, black epidermal metastases were noted on his left thigh. PET/CT revealed a hypermetabolic zone at the level of the small bowel. Owing to the possibility of surgical removal of this lesion, capsule endoscopy was carried out to visualize the lesion and to exclude other small-bowel metastases.

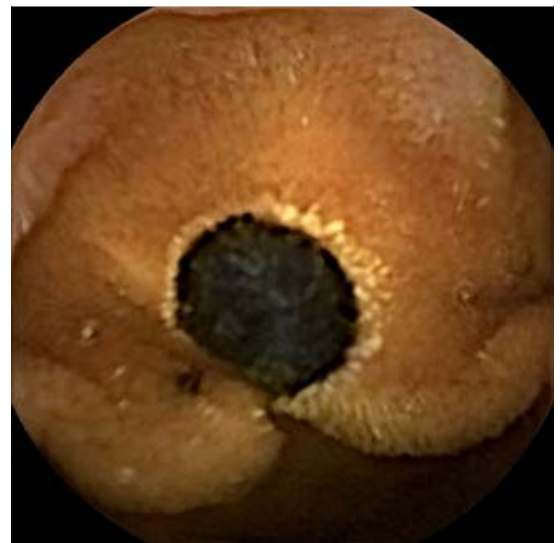

Fig. 1 The "solar eclipse" appearance of the coal-black metastasis encircled by whitish jejunal villi.

- Fig. 1 shows a metastatic lesion; we selected this image from among several melanoma metastases that were found. We have described the appearance of the coal-black lesion as "solar eclipse" appearance: the central coal-black lesion is encircled by whitish intestinal villi following disappearance, with systemic treatment, of the melanocytes in the area surrounding the metastasis. Numerous metastatic lesions were found throughout the small bowel, because of which surgical intervention was not considered. More multicenter studies are need on PET/CT, video capsule endoscopy, and other modalities for imaging the small bowel to define the best algorithm to follow in cases with suspected dissemination of melanoma.
Endoscopy_UCTN_Code_CCL_1AC_2AC

D. Urbain ${ }^{1}$, M. Aerts ${ }^{1}$, H. Reynaert ${ }^{1}$, F. Mana', B. Neyns ${ }^{2}$

1 Department of Gastroenterology, UZ

Brussel, Brussels, Belgium

2 Center of Oncology, UZ Brussel, Brussels, Belgium

\section{References}

1 Urbain D, de Looze D, Demedts I et al. Videocapsule endoscopy in small-bowel malignancy: a multicenter Belgian study. Endoscopy 2006; 38: $408-411$

2 Pennazio M, Rondonotti E, de Franchis R. Capsule endoscopy in neoplastic diseases. World J Gastroenterol 2008; 14: 5245-5253

3 Park J, Ostrowitz MB, Cohen MS, Al-Kasspooles $M$. A patient with metastatic melanoma of the small bowel. Oncology (Williston Park) 2009; 23: 98 - 102

4 Smedegaard J, Adamsen S. Metastatic malignant melanoma of the small intestine: capsule endoscopic appearance. Endoscopy 2007; 39: E209

\section{Bibliography}

DOI 10.1055/s-0029-1243941

Endoscopy 2010; 42: E185

(c) Georg Thieme Verlag KG Stuttgart · New York . ISSN 0013-726X

\section{Corresponding author \\ D. Urbain, MD, PhD}

Department of Gastroenterology

UZ Brussel

Laarbeeklaan 101

1090 Brussels

Belgium

Fax: +32-2477-6810

daniel.urbain@uzbrussel.be 